\title{
Effect of Long-Term Exercise Training on Regional Myocardial Perfusion Changes in Patients With Coronary Artery Disease
}

\author{
Li Linxue, MD; Ryuji Nohara, MD; Shigeru Makita, MD*; Ryohei Hosokawa, MD; \\ Tatsuhiko Hata, MD; Kazumi Okuda, MD*; Hiroshi Hamazaki, PhD**; \\ Masatoshi Fujita, MD***; Shigetake Sasayama, MD
}

\begin{abstract}
The cardiac rehabilitation of patients with coronary artery disease (CAD) promotes exercise tolerance, improves left ventricular function, and decreases the heart rate and systolic blood pressure at the same load intensity. Several studies have shown that cardiac rehabilitation improves myocardial perfusion in CAD patients. However, the long-term ( $\geq 1$ year) effect of cardiac rehabilitation on myocardial perfusion is still controversial. The effect of long-term exercise training on myocardial perfusion in CAD patients was assessed using thallium$201\left({ }^{201} \mathrm{Tl}\right)$ exercise studies at a baseline (4 months after the onset of CAD) and at a 1-year or more follow-up in 58 patients with stable CAD. The subjects had been divided into a training group $(n=35)$ participating in supervised exercise 2 times per week for the follow-up period, and the control group $(n=23)$. There was an improvement in the myocardial perfusion on stress ${ }^{201} \mathrm{Tl}$ scintigraphy in 20 of the $35(57.1 \%)$ trained patients and in 3 of the $23(13.0 \%)$ of the control patients $(\mathrm{p}<0.001)$. The number of ${ }^{201} \mathrm{Tl}$ stress myocardial perfusion defect segments was significantly decreased after the cardiac rehabilitation training (231 to 153 segments), but showed no change in the control group (158 to 156 segments) ( $\mathrm{p}<0.01)$. In spite of no significant differences in the number of involved coronary arteries, it improved (12/17 patients: $70.6 \%$ ) more in the patients who had trained for more than 2 years compared to the patients who had trained for less than 2 years. The exercise tolerance increased in 25 of the 35 training group patients $(71.4 \%)$, and in only 3 of the 23 control group patients (13.0\%). The peak double products increased from $20,131 \pm 6,010$ to $28,370 \pm 5,600(\mathrm{p}<0.01)$ in the training group, and showed no change in the control group (20,567 $\pm 5,112$ to $20,964 \pm 7,728$ (NS)). The results indicated that the long-term physical training increased exercise tolerance and the double products of CAD patients. In addition, the training resulted in improved cardiac perfusion as evidenced by ${ }^{201} \mathrm{Tl}$ scintigraphy. The findings suggest that exercise training is an advisable and effective treatment for patients with CAD. (Jpn Circ J 1999; 63: 73-78)
\end{abstract}

Key Words: Coronary artery disease; Exercise training; Thallium-201 myocardial scintigraphy

$\mathbf{E}$ xercise training has been shown to promote exercise tolerance, improve left ventricular function, and decrease the heart rate and systolic blood pressure at the same work load intensity in patients with coronary artery disease (CAD)!-5 Although several studies have shown an improvement of myocardial perfusion in CAD patients from cardiac rehabilitation, the effects of such rehabilitation on myocardial perfusion are not entirely clear $^{6,7}$ and the effects of long-term exercise training on myocardial perfusion in patients with CAD have also not been investigated. The Cardiac Rehabilitation Research Group of Kyoto University has been providing group sports exercise therapy for patients with CAD since 1982, and has reported the effects of this exercise therapy?,8 In the present study, we analyzed the scintigraphic data of thallium-201 single photon emission computed topography

(Received July 3, 1998; revised manuscript received October 14, 1998; accepted October 16, 1998)

Department of Cardiovascular Medicine, Kyoto University, Graduate School of Medicine, *Takeda Hospital, **Study Group of Cardiac Sports Rehabilitation, Kyoto University and $* * *$ College of Medical Technology, Kyoto University, Kyoto, Japan

Mailing address: Ryuji Nohara, MD, Department of Cardiovascular Medicine, Kyoto University, Graduate School of Medicine, 54 Kawaracho, Shogoin, Sakyoku, Kyoto 606, Japan
(201Tl SPECT) in patients with CAD to evaluate the effect of long-term (1-5 years) exercise training on myocardial perfusion. To our knowledge, no previous investigation has used serial ${ }^{201} \mathrm{Tl}$ images to quantitate changes in myocardial perfusion in CAD patients undergoing exercise cardiac rehabilitation in compared with a control group. We also evaluated the effects of the length of the rehabilitation training period on the improvement of perfusion.

\section{Methods}

\section{Patients and Protocol (Table 1)}

Fifty-six patients with CAD who had an old myocardial infarction (at least 4 months before) or who had stable exertional angina completed an exercise test at Kyoto University Hospital. They were divided into training and control groups by their own choice.

Thus, 35 patients aged $49-72$ years $(63 \pm 6$ years, 29 males, 6 females) participated in long-term (18 patients: 1 2 years, 17 patients: $\geq 2$ years) (mean $27.2 \pm 18.9$ months) physical exercise training for cardiac rehabilitation. Their mean bodyweight was $62 \pm 7 \mathrm{~kg}$. Twenty-three of the training group patients had single-vessel-disease (significant stenosis $\geq 75 \%$ ); 6 had double-vessel and 6 had triple-vessel disease. Thirty-one $(88.6 \%)$ patients had high-grade (> 
Table 1 Clinical Characteristics of the Patients in the Training and Control Groups

\begin{tabular}{|c|c|c|c|}
\hline Clinical variables & $\begin{array}{r}\text { Training } \\
(n=35)\end{array}$ & $\begin{array}{c}\text { Control } \\
(n=23)\end{array}$ & $p$ value \\
\hline Age (years) & $63 \pm 6$ & $65 \pm 8$ & $N S$ \\
\hline Males/Females & $29 / 6$ & $19 / 4$ & $N S$ \\
\hline Myocardial infarction & $29(82.9)$ & $16(69.6)$ & $N S$ \\
\hline Angina pectoris & $6(17.1)$ & $6(26.0)$ & $N S$ \\
\hline Exercise induced angina & $3(8.6)$ & $3(13.0)$ & $N S$ \\
\hline$P T C A$ & $9(25.7)$ & $7(30.4)$ & $N S$ \\
\hline$C A B G$ & $5(14.3)$ & $3(13.0)$ & $N S$ \\
\hline \multicolumn{4}{|l|}{ Coronary angiography } \\
\hline Single vessel disease & $23(65.7)$ & $9(39.1)$ & \\
\hline Double vessels disease & $6(17.1)$ & $7(30.4)$ & \\
\hline Triple vessel disease & $6(17.1)$ & $7(30.4)$ & $N S$ \\
\hline $99 \sim 100 \%$ & 27 & 13 & $N S$ \\
\hline $75 \sim 90 \%$ & 4 & 3 & $N S$ \\
\hline $50 \sim 75 \%$ & 4 & 7 & $N S$ \\
\hline \multicolumn{4}{|l|}{ Heart failure } \\
\hline Class I & 28 & 19 & $N S$ \\
\hline Class II & 7 & 4 & $N S$ \\
\hline Mean bodyweight ( $k g$ ) & $62 \pm 7$ & $60 \pm 9$ & $N S$ \\
\hline$L V E F$ & $54 \pm 6$ & $54 \pm 6$ & $N S$ \\
\hline Diabetes mellitus & $6(17.1)$ & $5(21.7)$ & $N S$ \\
\hline Hypertension & $10(28.6)$ & $7(30.4)$ & $N S$ \\
\hline Hyperlipidemia & $9(25.7)$ & $7(30.4)$ & $N S$ \\
\hline
\end{tabular}

Parentheses $=(\%) ;$ PTCA, percutaneous transluminal coronary angioplasty; $C A B G$, coronary artery bypass graft; LAD, left anterior descending coronary artery; LCX, left circumflex coronary artery; RCA, right coronary artery; $L V E F$, left ventricular ejection fraction.

Heart failure was classified by the New York Heart Association criteria.

$90 \%$ ) coronary stenosis. Twenty-nine patients had had a myocardial infarction (17 inferior and/or lateral, 12 anterior and/or septal). Their mean ejection fraction was $54 \pm 6 \%$ on left ventriculography. Nine patients had undergone percutaneous transluminal coronary angioplasty (PTCA), and 5 had undergone coronary artery bypass grafting (CABG). Four patients had thrombolysis therapy during the acute phase of their myocardial infarction. In the training program, each patient underwent regular medically supervised exercise twice weekly consisting of walking, bicycling, jogging, swimming and sports training (gymnastics, tabletennis, badminton, mini-tennis) for 1.5 -h sessions. The exercise was prescribed at individually targeted intensities, $60-85 \%$ of the measured maximal heart rate determined during an initial test. The target heart rate was determined using Karvonen's formula (Target heart rate $=$ (Maximal heart rate-resting heart rate) $\times a+$ resting heart rate)? The a value ranged from 0.6 to 0.9 in accordance with individual levels of cardiac function. Generally the exercise training was initially performed under ECG monitoring for 3 months and it was suggested that exercise training continue for at least 1 year. Approximately 900-1,000 calories were expended by each patient per week in the training.

The 23 patients who were enrolled in the control group were from 50 to 71 years old $(65 \pm 8$ years, 19 males, 4 females) (study participation, mean 26.0 \pm 12.5 months), and their mean bodyweight was $60 \pm 9 \mathrm{~kg}$. Nine patients had single-vessel, and 7 patients had double-vessel or triplevessel disease. Sixteen $(69.5 \%)$ patients had high-grade (>90\%) coronary stenosis. Sixteen patients had myocardial infarction (10 inferior and/or lateral, 6 anterior and/or septal). Their mean ejection fraction was $54 \pm 6 \%$ on left ventriculography. Seven patients had undergone PTCA and 3 CABG. The same test protocol was used as for the train- ing patients. The control patients did not participate in exercise or sports training and did not engage in regular aerobic exercise during the follow-up periods; they otherwise lived a normal home life with low intensity activity.

The period between the time when the onset of CAD was detected and the baseline exercise test with ${ }^{201} \mathrm{Tl}$ myocardial SPECT was more than 4 months in all patients. There was no significant difference in gender, age, or bodyweight between the 2 groups. The initial test was performed before the patient started the cardiac rehabilitation or immediately after starting the training, and the follow-up test was performed during the exercise training period. The cardiac rehabilitation program started 2 weeks to 6 months after the patient's discharge. No relapse of CAD or exacerbation of symptoms was observed between the 2 tests in any patients. No major drug treatment (including nitrates, $\mathrm{Ca}^{++}$antagonist, $\beta$-blocker, ACE inhibitor and cholesterollowering drugs) was stopped or changed during the study period or just before the study. SPECT study was done without stopping medication. The total cholesterol level was $231 \pm 38 \mathrm{mg} / \mathrm{dl}$ in the training group, and $240 \pm 43 \mathrm{mg} / \mathrm{dl}$ in the control group. The LDL-cholesterol level was $140.3 \pm$ $37.5 \mathrm{mg} / \mathrm{dl}$ in the training group and $140.7 \pm 35.6 \mathrm{mg} / \mathrm{dl}$ in the control group. Because several participants in the 2 groups were being treated with cholesterol-lowering drugs, the lipid values were not assessed in this study. There were no significant differences in the use of prescription drugs between the control and training groups, and there were no notable dietary changes in the follow-up period.

\section{Exercise ${ }^{201} \mathrm{Tl}$ SPECT}

All of the patients performed an exercise test on a treadmill, with a Bruce protocol. ${ }^{201} \mathrm{Tl}$ (74.0-92.5 MBq) was injected through an antecubital vein at the time of symptomlimited peak exercise ( $2 \mathrm{~mm}$ horizontal down-sloping ST depression on the ECG, and/or severe angina or fatigue), and the patients were instructed to continue the exercise for one more minute at the same work load after the injection of $201 \mathrm{Tl}$.

Imaging was performed to obtain 32 projection images for $30 \mathrm{~s}$ each over $180^{\circ}$ from $45^{\circ}$ left posterior oblique to $45^{\circ}$ right anterior oblique immediately after the exercise, and again $3 \mathrm{~h}$ after exercise in the identical projections. A General Electric $400 \mathrm{AC} / \mathrm{T}$ model camera equipped with a low-energy general-purpose collimator was used for image and data acquisition. Follow-up studies were carefully performed with the same camera angles and overlays to assure the same camera placement.

\section{Image Analysis}

The semi-quantitative analysis of the serial myocardial images was performed according to the method previously described 10 Each image was divided into 20 segments (anterior, anteroseptal, inferoseptal, interior, inferolateral, high lateral, anteroapical, inferoapical regions) to assess the ${ }^{201} \mathrm{Tl}$ uptake using a 4-point grading system: $0=$ normal; $1=$ mildly reduced; $2=$ moderately reduced; and $3=$ defect (Fig 1). All of the defect scores were summed for each patient. The evaluation of the follow-up results was also determined by this scoring. Improvement by 2 points or more was regarded as 'improvement', worsening by 2 points or more was regarded as 'worsened', and changes within 2 points were regarded as 'no change'!1,12 The ${ }^{201} \mathrm{Tl}$ myocardial SPECT images were evaluated by 3 nuclear cardiologists with no knowledge of the exercise test proto- 

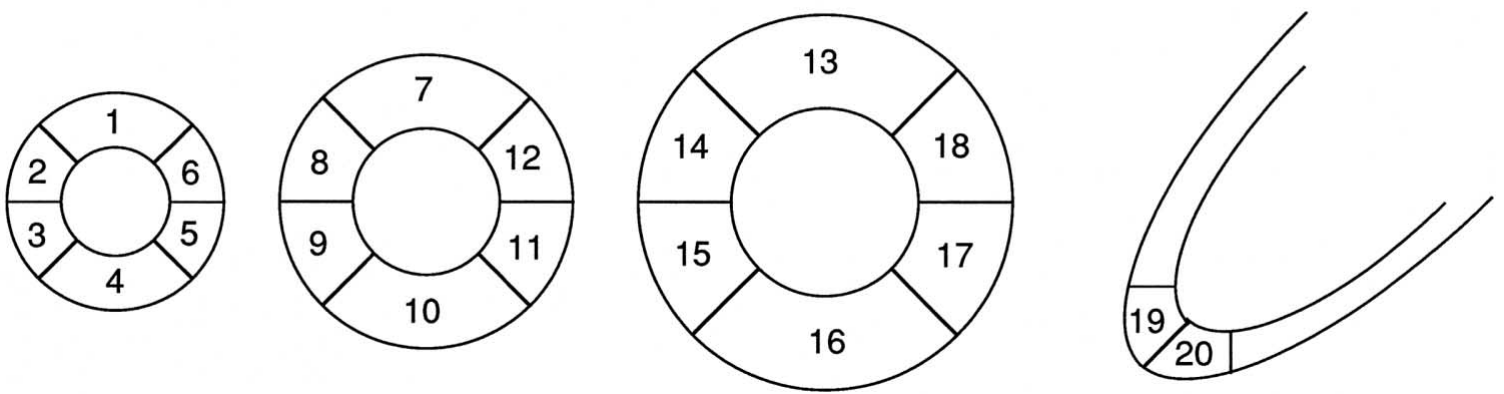

Fig 1. Interpretation of ${ }^{201} \mathrm{Tl}$ images of the left ventricle. It was devided into 18 anatomic short-axis regions and 2 long-axis apical regions: $1,7,13=$ anterior; $2,8,14=$ anteroseptal; $3,9,15=$ inferoseptal; $4,10,16=$ interior; $5,11,17=$ inferolateral; $6,12,18=$ high lateral; $19=$ anteroapical; $20=$ inferoapical regions. Thallium uptake was visually scored: $0=$ normal uptake; $1=$ mild reduction of activity; $2=$ moderate reduction of activity; $3=$ severe reduction of activity or defect.
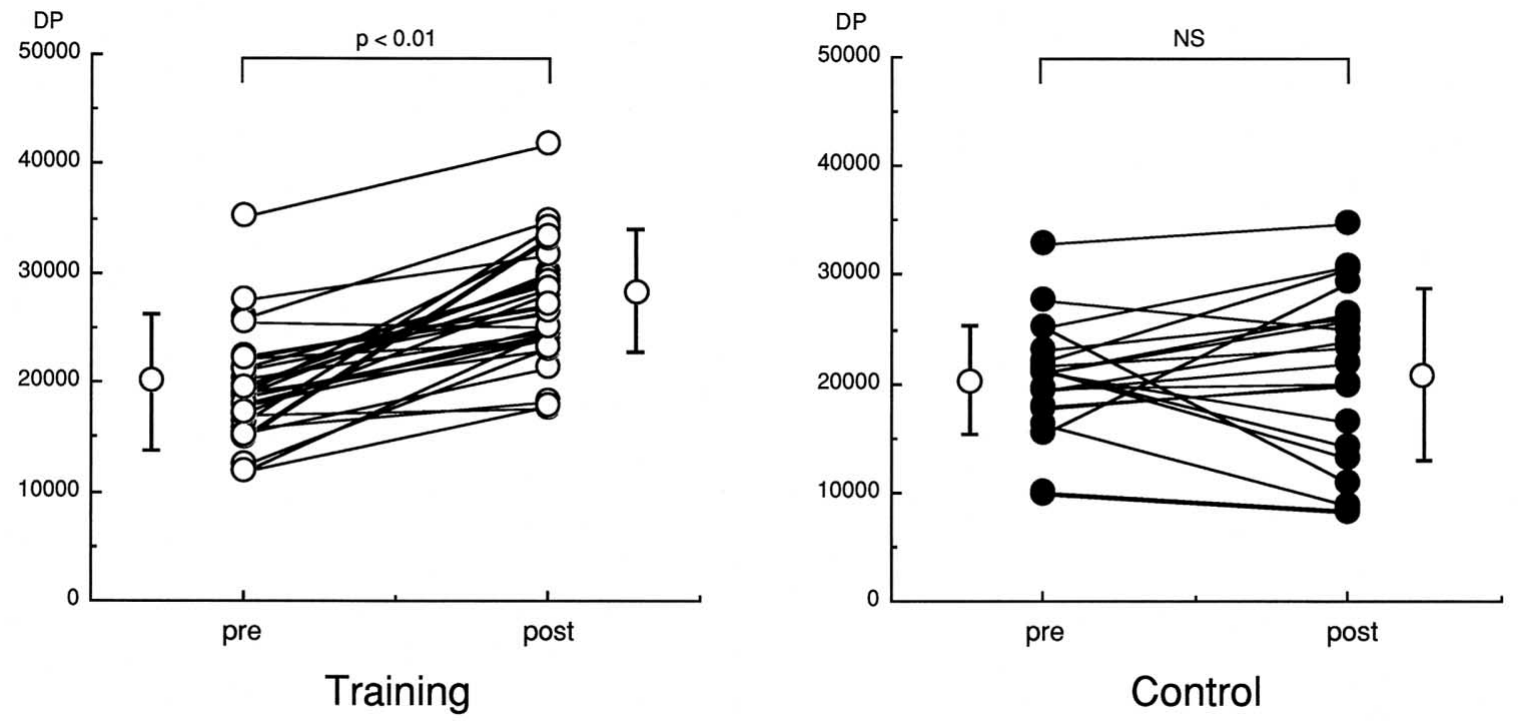

Fig 2. Attained peak double products before and after training are shown for individual cases.

Table 2 Hemodynamic Variables During Exercise Testing

\begin{tabular}{|c|c|c|c|c|c|c|}
\hline & \multicolumn{2}{|c|}{ Training $(n=35)$} & \multirow{2}{*}{$p$ value } & \multicolumn{2}{|c|}{ Control $(n=23)$} & \multirow{2}{*}{$p$ value } \\
\hline & pre & post & & pre & post & \\
\hline Rest heart rate (beats/min) & $83 \pm 9$ & $77 \pm 12$ & $<0.05$ & $82 \pm 12$ & $83 \pm 15$ & $N S$ \\
\hline Maximal HR (beats/min) & $134 \pm 25$ & $149 \pm 17$ & $<0.05$ & $134 \pm 26$ & $124 \pm 26$ & $N S$ \\
\hline Maximal exercise time (s) & $463 \pm 81$ & $653 \pm 73$ & $<0.01$ & $476 \pm 128$ & $435 \pm 117$ & $N S$ \\
\hline Maximal SBP $(\mathrm{mmHg})$ & $156 \pm 21$ & $180 \pm 31$ & $<0.01$ & $167 \pm 32$ & $166 \pm 46$ & $N S$ \\
\hline Maximal DP $(H R \times S B P)$ & $20131 \pm 6010$ & $28370 \pm 5600$ & $<0.01$ & $20567 \pm 5112$ & $20964 \pm 7728$ & $N S$ \\
\hline
\end{tabular}

$H R$, heart rate; SBP, systolic blood pressure; DP, double products.

col or the patients' histories. Interobserver variance was $98 \%$ and $93 \%$ at the anterior and inferior wall, respectively, as reported before! ${ }^{1}$ Intraobserver variance was $97 \%$, evaluated by 3 examiners.

\section{Statistical Analysis}

Student's $t$ test and the Chi-square test were used for the comparisons of the training and control groups. Each value is expressed as the mean $\pm \mathrm{SD}$, and a value of $\mathrm{p}<0.05$ was regarded as significant.

\section{Results}

Exercise Test

A significant long-term training effect was revealed in the trained patients as assessed by the resting and maximal heart rates, exercise time, and maximum rate-pressure product (Table 2). The resting heart rate in the trained group decreased from $83 \pm 9$ beats/min to $77 \pm 12$ beats/min $(\mathrm{p}<0.05)$, whereas the resting heart rate in the control group did not change $(82 \pm 12$ to $83 \pm 15$ beats/min (NS)). The exercise time increased significantly, from $463 \pm 81$ to $653 \pm 73 \mathrm{~s}$ 


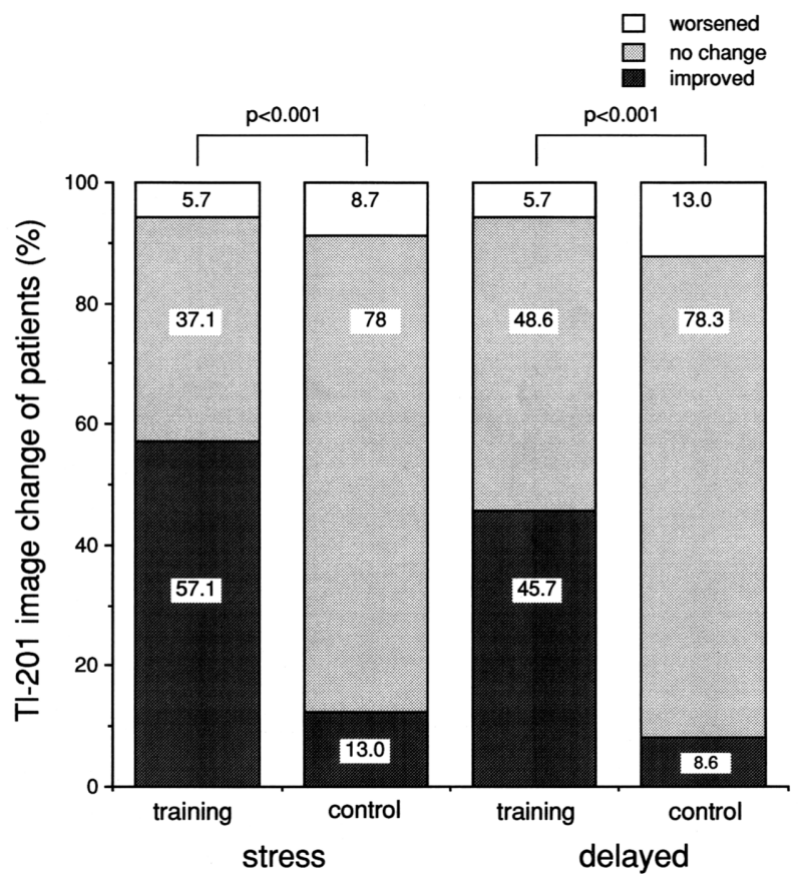

Fig 3. Comparison of ${ }^{201} \mathrm{Tl}$ defect improvement before and after cardiac rehabilitation between the rehabilitation and control groups.

$(\mathrm{p}<0.01)$ in the trained group, and did not change from $476 \pm 128$ to $435 \pm 117 \mathrm{~s}$ in the control group (NS). The peak rate-pressure products in the trained group all increased from $20,131 \pm 6,010$ to $28,370 \pm 5,600(\mathrm{p}<0.01)$, and showed no change in the control group $(20,567 \pm 5,112$ to $20,964 \pm$ 7,728) (Fig 2). The resting double products in the training group showed no change between before and after the intervals $(9,605 \pm 450$ before, and 9,320 \pm 520 after the training), and also showed no change in the control group $(9,820 \pm 820$ and $9,992 \pm 920)$. Three patients of the training group had $\geq 2 \mathrm{~mm}$ ECG ST depression on the initial and second training follow-up test, as did 2 patients in the control.

\section{Thallium-201 Analysis}

Three patients in the training group showed a small myocardial perfusion abnormality in the baseline ${ }^{201} \mathrm{Tl}$ SPECT study, as did 1 patient in the control group. The ${ }^{201} \mathrm{Tl}$ stress myocardial perfusion improvement was obtained in 20 of the $35(57.1 \%)$ training group patients, and in 3 of the $23(13.0 \%)$ control group patients. A delayed ${ }^{201} \mathrm{Tl}$ study was performed in 16 of the $35(45.7 \%)$ trained patients and in 2 of the $23(8.6 \%)$ control patients $(\mathrm{p}<$ 0.001 ) (Fig 3 ). The number of abnormal perfusion segments in stress images decreased in the trained group from $231(33 \%)$ to $153(21.9 \%)(\mathrm{p}<0.01)$ of 700 segments, and from $158(34.3 \%)$ to $156(33.9 \%)$ of 460 segments in the control group (NS). On the delayed images, the number decreased from $201(28.7)$ to $175(25.0 \%)$ segments in the training group $(\mathrm{p}<0.05)$, and from $146(31.7 \%)$ to 144 $(31.3 \%)$ segments in the control (NS) (Fig 4). A significant improvement of coronary perfusion was observed among the patients who had undergone training for more than 2 years compared to the patients who had trained for less than 2 years during the follow-up period $(12 / 17,70.6 \%$ vs $8 / 18,44.4 \%)(\mathrm{p}<0.05)$. These results were not affected by

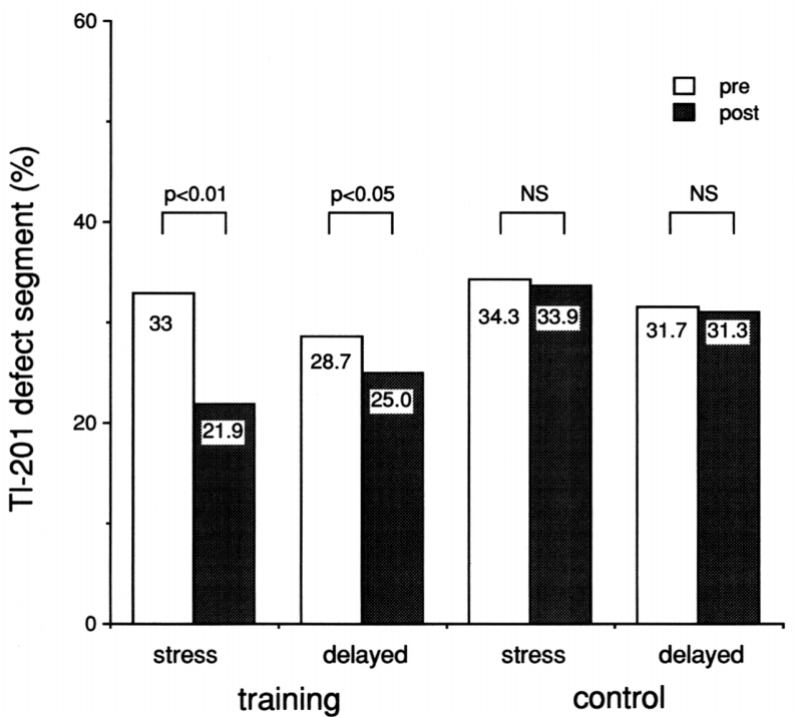

Fig 4. Comparison of ${ }^{201} \mathrm{Tl}$ defect segments of myocardial perfusion before and after cardiac rehabilitation between the 2 groups of CAD patients (training group $=35$, control group $=21$ ).

the number of coronary arteries involved (single/multivessel disease; 4/13:<2 years, 4/14: $\geq 2$ years). However, the results were from the comparison between the 2 different groups in which the background was not completely the same. No significant difference in perfusion improvement was observed among the training group patients with single-vessel, double-vessel and triple-vessel disease. In the training group, no myoeardial infarction, no heart failure or unstable angina were seen in the follow-up period. Three patients had stable angina. One took diuretic medicine 2 days. In the control group, however, 1 had nonsustained ventricular tachycardia attack, 1 had CABG performed because of unstable angina, and 1 was admitted for a few days because of heart failure. Two patients had stable angina in the follow-up period.

\section{Discussion}

In our study group, cardiac sports rehabilitation has been conducted in patients with CAD for the past 13 years. The safety of this rehabilitation, as well as its peripheral and psychologic effects, has been reported2,8 Because of difficulties in the evaluation of patients who undergo chronic cardiac rehabilitation compared with sedentary patients, there is almost no relevant systemic data obtained using perfusion scintigraphy with ${ }^{201} \mathrm{Tl}$. The present study showed positive data in terms of cardiac rehabilitation as a nonmedication treatment for myocardial perfusion.

Recent research suggests that a definite improvement in exercise performance can be brought about by cardiac rehabilitation using aerobic exercise for patients with chronic CAD. Although exercise training has been shown to improve exercise tolerance and left ventricular function, decrease the rate-pressure products, and improve the ST depression to a submaximal point ${ }^{13-15}$ the mechanism by which exercise improves ischemia is not clearly understood. Animal studies, however, have demonstrated that chronic exercise can result in improved myocardial function and perfusion! 16,17

Numerous techniques, including ${ }^{201} \mathrm{Tl}$ scintigraphy, have 
been used to assess changes in myocardial perfusion. However, a consensus has not been reached regarding the improvement in perfusion from the perspective of nuclear cardiology. Some studies have investigated the effect of cardiac rehabilitation on myocardial perfusion in CAD patients, but obtained no significant results ${ }^{18-20}$ An assessment of patients by Froelicher et al ${ }^{18}$ with ${ }^{201} \mathrm{Tl}$ scintigraphy following 3-13 months of exercise indicated a subtle improvement in 6 of the patients, but this was not quantified. In 1990, Nohara et al reported an improvement in myocardial perfusion on ${ }^{201} \mathrm{Tl}$ early images in 7 of $18 \mathrm{CAD}$ patients $(39 \%)$ and on the delayed image in 5 of the 18 patients $(28 \%)$ ? However, no significant difference from the control group (consisting of a small number of subjects) was demonstrated. Our present study was designed to investigate the effect of long-term exercise training on the myocardial perfusion of CAD patients, and we found that the exercise tolerance in the training group was significantly improved compared with the control group, and an improvement in stress ${ }^{201} \mathrm{Tl}$ myocardial perfusion was observed in $57.1 \%$ of the patients in the training group. Buda et al compared patients' exercise scintigraphy findings 3 weeks after acute myocardial infarction (AMI) to those at 3 months after AMI21 They suggested that a central improvement resulted in a spontaneous improvement of myocardial perfusion in some patients. In the present study, the period from the onset of AMI or attack of angina pectoris to the initial ${ }^{201} \mathrm{Tl}$ examination was more than 4 months in all of the patients. Therefore, there may be a small possibility of spontaneous improvement in these patients. In addition, improvement in myocardial perfusion according to different exercise periods of rehabilitation had not yet been reported. The present study showed a significant improvement in myocardial perfusion in selected patients who had continued the long-term cardiac rehabilitation therapy for more than 2 years, although the patient group was not evaluated serially through these years.

The mechanism by which exercise-based rehabilitation improves myocardial perfusion remains unclear. Animal studies demonstrated improvement in left ventricular function and perfusion as well as an increase in the collateral circulatory pathway.2 In humans, it has not been demonstrated whether or not an increase in the collateral circulatory pathway caused by rehabilitation improves the myocardial blood flow. In other words, it is very difficult to judge whether the improvement in myocardial perfusion after rehabilitation increases the collateral circulatory pathway, or whether the amelioration of the underlying main coronary artery lesions facilitates the collateral circulation. Exercise may also cause ischemia in the regions where the collateral circulatory pathway is responsible for perfusion. Improvement in the main circulation not depending on the collateral circulation and improvement in the degree of stenosis have also been suggested. According to recent studies, the regression of coronary atherosclerosis occurs after physical activity expending $2200 \mathrm{kcal}$ or more per week? It is extremely difficult for a CAD patient to perform this amount of exercise in a physical conditioning program, but this finding of regression cannot be denied. It may be related to the improvement in risk factors such as a cholesterol-lowering effect that is observed in a long rehabilitation period ( 2 years) and not in a short period ${ }^{23}$ It was reported that cholesterol-lowering treatment improved the flow reserve by endothelium-dependent coronary vasodilation. ${ }^{24}$ It was also reported that in the hypertensive heart, suppressed flow reserve may recover after antihypertensive treatment. 5 Thus, exercise may indirectly improve vasodilation and flow reserve through a cholesterol-lowering or anti-hypertensive effect.

In addition, exercise was reported to directly influence the production of nitric oxide, following an improvement in endothelium dysfunction 26 All of these factors may be responsible for the perfusion improvement brought about by exercise.

It is also unclear why training improved the delayed rest images in the present patients. The delayed images of 14 patients improved: 9 of them had been revascularized, 3 of them had angina pectoris, and 4 had single-vessel disease. There may be some relation between this result and improved left ventricular wall motion?, myocardial function, ${ }^{201} \mathrm{Tl}$ uptake and washout ${ }^{6}$ due to recovery from repetitive stunning, or improved cholesterol 22 In addition, improvement of the endothelium-dependent flow of epicardial circulation and micro-circulation would affect the rest image?

In the present study, the exercise tolerance of the patients increased significantly after rehabilitation, and other parameters including the heart rate, blood pressure and double products were also improved. Various factors including the period of rehabilitation, exercise intensity, degree of ischemia and risk factors may contribute to the improvement in these parameters. The prolongation of the exercise time and increases in the double products with the improvement in myocardial perfusion suggested an active improvement of the myocardial oxygen supply, which was supported by the ${ }^{201} \mathrm{Tl}$ SPECT data. We have therefore demonstrated the central adaptation to long-term exercise therapy of the cardiac muscle itself. Ehsani et al reported that relatively short-term moderate-to-high intensity endurance exercise training in older sedentary men can induce cardiac adaptations characterized by a modest volume overload, left ventricular hypertrophy, and improvement of left ventricular systolic function at peak exercise ${ }^{28}$ Our cardiac rehabilitation using moderate intensity exercise proved to be effective even for patients with ischemic heart disease.

\section{Study Limitations}

This study was performed over a 5-year period, and several medical facilities participated; thus not all of the original patients (with and without long-term physical training) could be followed up using ${ }^{201} \mathrm{Tl}$ SPECT. The number of subjects was not large enough, and less than half of the subjects underwent rehabilitation for more than 2 years. The follow-up study was not conducted with ${ }^{201} \mathrm{Tl}$ perfusion at the same exercise load as that used in the baseline study. There was also no follow-up data regarding dietary and cholesterol changes. All of these limitations should be overcome in future studies.

\section{Conclusions}

The effects of long-term exercise cardiac rehabilitation on myocardial perfusion were assessed using thallium-201 SPECT imaging in patients with chronic coronary artery disease. The rehabilitation produced a significant improvement in the exercise tolerance and ${ }^{201} \mathrm{Tl}$ myocardial perfusion, suggesting that long-term cardiac rehabilitation is an advisable and effective treatment for patients with chronic coronary artery disease. 


\section{Acknowledgments}

We thank Dr Michael L. Pollock for reviewing our paper and giving instructive suggestions, and Dr Terumitsu Tanaka and Dr Shinji Ono for their clinical support and advice. We also thank Ms Naoko Takemoto and Mr Daniel Mrozek for their technical and linguistic help in the preparation of this manuscript.

\section{References}

1. Jensen D, Atwood JE, Froelicher V, McKirnan MD, Battler A, Ashburn W, et al: Improvement in ventricular function during exercise studied with radionuclide ventriculography after cardiac rehabilitation. Am J Cardiol 1980; 46: 770-777

2. Nohara R, Okuda K, Ono S, Makita S, Mohiuddin H, Sasayama S: Age-wise analysis of the effect of long term group exercise therapy in patients with ischemic heart disease. Cardiol Elderly 1994; 2: $113-118$

3. Sukkivan M, Ahnve S, Froelicher V, Meyers J: The influence of exercise training on the ventilatory threshold of patients with coronary heart disease. Am Heart J 1985; 109: 458 -463

4. Dressendorfer RH, Smith JL, Amsterdam EA, Mason DT: Reduction of submaximal exercise myocardial oxygen demand post walk training program in coronary patients due to improved physical work efficiency. Am Heart J 1982; 103: 158- 162

5. Hambrecht R, Niebauer J, Marburger C, Grunze M, Kälberer B, Hauer K, et al: Various intensities of leisure time physical activity in patients with coronary artery disease: effects on cardiorespiratory fitness and progression of coronary atherosclerotic lesions. J Am Coll Cardiol 1993; 22: 468-477

6. Sebrechts CP, Klein JL, Ahnve S, Froelicher VF, Ashburn WL: Myocardial perfusion changes following 1 year of exercise training assessed by thallium-201 circumferential count profiles. Am Heart $J$ 1986; 112: $1217-1226$

7. Verani MS, Hartung GH, Hoepfel HJ, Welton DE, Pratt CM, Miller RR: Effect of exercise training on left ventricular performance and myocardial perfusion in patients with coronary artery disease. Am J Cardiol 1981; 47: 797-803

8. Nohara R, Kambara H, Mohiuddin IH, Ono S, Okuda K, Makita S, et al: Cardiac sports rehabilitation for patients with ischemic heart disease. Jpn Circ J 1990; 54: 1443-1450

9. Karvonen M, Kentala E, Mustala O: The effect of training on heart rate: A longitudinal study. Ann Med Exp Biol Fenn 1957; 35: $307-$ 315

10. Tartagni F, Fallani F, Corbelli C, Balletta A, Franch R, Lombardi A, et al: Detecting hibernated myocardium with SPECT and thalliumglucose-insulin infusion. J Nucl Med 1995; 36: 1377-1383

11. Nohara R, Kambara H, Suzuki Y, Tamaki S, Kadota K, Kawai C, et al: Stress scintigraphy using single-photon emission computed tomography in the evaluation of coronary artery disease. Am J Cardiol 1984; 53: 1250-1254

12. Gordon NF, Fruger PE, Hous B, Cillires JF: Improved exercise ventilatory responses after training in coronary heart disease during long term beta-adrenergic blockade. Am J Cardiol 1983; 51: 755-758

13. Conn EH, Williams RS, Wallace AG: Exercise responses before and after physical condition in patients with severely depressed left ventricular function. Am J Cardiol 1982; 49: 296-300

14. Ehsani AA, Heath Gh, Hagberg JM, Sobel BE, Holloszy JO: Effects of 12 months of intense exercise training on ischemia ST segment depression in patients with coronary artery disease. Circulation 1981; 65: 1116-1124

15. Maddahi J, Carcia EV, Berman DS, Waxman A, Swan HJC, Forreser $\mathrm{J}$ : Improved non-invasive assessment of coronary artery disease by quantitative analysis of regional stress myocardial distribution and washout of thallium-201. Circulation 1981; 64: 924-930

16. Grohs JG, Fischer G, Raberger G: Cardiac and hemodynamic effects of diltiazem during exercise-induced myocardial dysfunction in dog. J Cardiovasc Pharmacol 1990; 16: 228-233

17. Goldman L, Hashimoto B, Cook F, Loscalzo A: Comparative reproducibility and validity of systems for assessing cardiovascular functional class: advantages of a new specific activity scale. Circulation 1981; 64: $1227-1234$

18. Froelicher V, Jensen D, Atwood JE, McKirnan MD, Gerber K Slutsky R, et al: Rehabilitation: Evidence for improvement in myocardial perfusion and function. Arch Phys Med Rehabil 1980; 61: $517-522$

19. Tubau J, Witztum K, Froelicher V, Jensen D, Atwood E, McKirnan $\mathrm{M}$, et al: Noninvasive assessment of changes in myocardial perfusion and ventricular performance following exercise training. Am Heart $J$ 1982; 104: $238-248$

20. Williams MA, Maresh CM, Eterbrooks DJ, Hardrecht JJ, Sketch $\mathrm{MH}$ : Early exercise training in patients older than 65 years compared with that in younger patients after acute myocardial infarction or coronary bypass grafting. Am J Cardiol 1985; 55: 263-266

21. Buda AJ, Dubbin JD, Macdonald IL, Strauss HD, Orr SA, Meinddok $\mathrm{H}$ : Spontaneous changes in thallium-201 myocardial perfusion imaging after myocardial infarction. Am J Cardiol 1982; 50: 1272 1278

22. Roth DM, White FC, Nichols ML, Dobbs SL, Longhurst JC, Bloor CM: Effect of long-term exercise on regional myocardial function and coronary collateral development after gradual coronary artery occlusion in pigs. Circulation 1990; 82: 1778-1782

23. Abby C, William L, Deborah R, Roberta K, Marcial L: Long-term effects of varying intensities and formats of physical activity on participation rates, fitness, and lipoproteins in men and women aged 50 to 65 years. Circulation 1995; 91: 2596-2604

24. Treasure CB, Klein JL, Weintraub WS, Talley JD, Stullabower ME, Kosinski AS, et al: Beneficial effect of cholesterol lowering therapy on the coronary endothelium in patients with coronary artery disease. N Engl J Med 1995; 332: 481 -487

25. Palodi O, Neghia D, Sawbuceti G, Marabotti C, Donat OL: Regional myocardial blood flow and coronary reserve in hypertensive patients: The effect of therapy. Drugs 1992; 44(Suppl 1): 48-55

26. Sessa WC, Pritchand K, Seyedi N, Warg J, Hintze TH: Chronic exercise in dogs increases coronary vascular NO production and endothelial cell NO synthase gene expression. Circ Res 1994; 74: 349-353

27. Hasdai D, Gibbons RJ, Holmes DR, Higano ST, Lerman A: Coronary endothelial dysfunction in humans is associated with myocardial perfusion defects. Circulation 1997; 96: 3390-3395

28. Ehsani AA, Ogawa T, Miller TR, Spina RJ, Jilka SM: Exercise training improves left ventricular systolic function in older men. Circulation 1991; 83: 96-103 